\title{
Research on Mixed Teaching of "Microcomputer Principle and Interface Technology" Course Based on MOOC
}

\author{
Rui Liang \\ Electronic Science teaching and research room, Xi'an FanYi University Taiyigong Town, Changan \\ District, Xi'an City, Shanxi Province, China \\ 948793038@qq.com
}

Keywords: MOOC; Microcomputer principle and interface technology; Hybrid teaching; Teaching reform

\begin{abstract}
In this paper, based on the teaching status of microcomputer principle and interface technology course, a hybrid teaching method based on MOOC "Microcomputer Principle and Interface Technology" course is proposed. The teaching method combines the MOOC platform with the traditional classroom, and makes full use of the MOOC teaching resources to achieve efficient classroom learning. Students need to learn MOOC content in advance, and teachers need to prepare lessons according to the MOOC learning situation of the students. It has been proved by practice that this teaching method makes the lectures in the classroom more prominent, the learning efficiency is improved, the students' grades are generally improved, and the overall teaching effect is good.
\end{abstract}

\section{Introduction}

The first priority of college education reform is to improve the quality of teaching. The classroom teaching mode is the most direct factor affecting the quality of teaching. The innovative teaching mode helps students to better learn knowledge. MOOC (Massive Open Online Courses), a large open online course, a free online learning platform set up by the top universities in the United States in 2012, providing learning opportunities for more students. At present, China has MOOC platforms such as Chinese college students' enemies and love courses[1].

Taking the course of microcomputer principle and interface technology as an example, this paper combines the traditional teaching of this course with MOOC to study a hybrid teaching method based on MOOC. After practice, this method is suitable for the teaching of this course. Students have a deep understanding of the principle and interface technology of computer microprocessors and have achieved certain results.

\section{Teaching Status of "Microcomputer Principles and Interface Technology" Course}

Microcomputer principle and interface technology are professional basic courses of electronic information. The main contents include the internal structure principle of 8086/8088CPU, assembly language and interface technology. The course is theoretical, abstract, and difficult to understand. Taking the electronic information science and technology major of the School of Engineering and Technology of Xi'an FANYI University as an example, the current teaching status of this course includes the following four points[2].

The teaching mode is mainly based on classroom teaching. Most of the courses are taught by traditional teaching methods, that is, classroom teaching. First of all, the content of this course is abstract and boring, and there are many knowledge points that need to be memorized. Traditional teaching teaching is seemingly boring. Because the contents of each chapter of the course are interlocking, the basic principles can't be remembered, which will lead to the inability of the follow-up content to form, and the situation that is becoming more and more unintelligible will eventually lead to students' tired of learning. Secondly, the difference in student base is a great challenge to teaching. Students with solid foundations are easy to understand and have strong 
ability to accept, while students with weak foundations may not be able to keep up with the progress of the lesson. Third, students' interest and importance in the course affect the effectiveness of the lectures. Students who are interested in and pay attention to the course are likely to accept passive teaching content, but not interested in this course will greatly reduce the effect of teaching, resulting in uneven learning levels and unsatisfactory learning results.

There are many contents, less class hours, and heavy learning tasks. According to the syllabus of the microcomputer principle and interface technology course of Xi'an FANYI University, the total teaching time of the course is 64 hours. In addition to 12 experimental hours, the actual theoretical teaching is 52 hours. The content of the textbook is 6 chapters, including basic knowledge, basic principles, assembly language programming and interface circuit design. The contents of each chapter are interlocked and can not be deleted. The limited amount of knowledge in a limited number of hours leads to a large number of lectures. It is a great test for the teachers and students.

The students' self-learning ability is poor, and the textbook preparation alone is not effective. The traditional teaching method requires students to prepare before class, but the poor self-learning ability of students can not grasp the key points, so the textbook preview effect is not good. At the same time, teachers have limited class time and cannot answer questions for each student individually. In the long run, this will cause students to lose interest in the course and lack motivation, which will ultimately affect the learning effect of this course.

The examination method is single. This course takes a three-seven-point score distribution method, which means $30 \%$ of the usual grades, and $70 \%$ is determined by the final paper score. However, there are many contents in this course. A test paper often does not fully reflect the semester of the course. At the same time, some students plagiarize their exams and pass the test, resulting in unfair test results.

\section{Advantages of MOOC-based hybrid teaching}

The "Love Course" network is a platform for the sharing of higher education curriculum resources supported by the "Undergraduate Teaching Quality and Teaching Reform Project of Higher Education" initiated by the Ministry of Education and the Ministry of Finance during the 12th Five-Year Plan period. The teaching method of the platform is MOOC teaching video. The lecturer is an excellent teacher in the relevant teaching field in China. The teaching method of the whole course is a point-to-point explanation[3]. The video is about 10 minutes short and 20 minutes long. In order to improve the visibility of the teaching process, multimedia teaching aids such as PPT and electronic whiteboard are often used in the lectures. In addition to the video, there is a discussion forum, a post-class practice area, etc. for students to exchange reviews[4]. Based on the network and based on public welfare, the MOOC platform provides high-quality educational resource sharing and personalized teaching services for universities, teachers, students and social learners.

The new teaching mode combining MOOC platform and traditional teaching can improve students' learning efficiency and help students to learn effectively in traditional classrooms and gain better knowledge. Specific advantages include the following:

Improve the teaching effect. Taking the teaching principle of the microcomputer principle and interface technology of Xi'an FANYI University as an example, the traditional instructor needs to prepare 90 minutes of teaching content, including the outline of the lecture content and the appropriate amount of exercises. The task is large under the whole class, and the student acceptance is not ideal. The mixed teaching based on MOOC requires students to watch the video for self-study before class, and take the problem to class; the teacher prepares the class according to the questions raised by the students in advance, and grasps the problems of the students' new content in advance, so as to improve the classroom teaching effect[5][6].

It is possible to repeat the study many times for free. The traditional teaching time is tight and the task is heavy. Especially for the course of microcomputer principle and interface, each knowledge point is interlocked, missed a little, and subsequent learning will be affected. MOOC 
can repeat the study on the website many times, and the video can also be downloaded free of charge. It can be repeated for the knowledge points with doubts, and it is a better way to learn for students with poor ability.

Meet the diverse needs of students at different levels. The MOOC platform is rich in resources, the quality of the course is high, and the lecturers are mostly famous teachers. For students with strong reception ability and excellent academic performance, in addition to listening to the lectures given by the class teacher, they can see more excellent teachers from the MOOC platform. Meet the diverse needs of students.

\section{Based on MOOC's "Microcomputer Principle and Interface Technology" Hybrid Teaching Design}

Overall design ideas. This design idea takes the example of the microcomputer principle and interface technology of the 2015 electronic information science and technology specialty of Xi'an FANYI University. The MOOC tutorial is the microcomputer principle and interface technology of Wu Ning, Xi'an Jiaotong University, Chinese University MOOC platform.

First of all, according to the school's microcomputer principle and interface technology syllabus and the specific content of selected textbooks, combined with the arrangement of MOOC teaching chapter of Xi'an Jiao Tong University, all the content is sorted out, and the content adapted to the students' learning is set up, and the learning objectives are set for the students[7].

Secondly, the students complete the preparation according to the learning objectives set by the teachers before the class, including the preparation of the textbook knowledge and the MOOC video learning, and complete the assignments in the MOOC discussion area. In addition to preparing lessons according to the textbook tradition, teachers are required to prepare lessons according to MOOC content[8]. The teacher monitors the student's learning situation, discussion situation and homework through the MOOC backstage, sorts out the problem and serves as an important basis for class teaching.

Finally, at the end of the period, students will be assessed according to their usual preparations, lectures and assignments. The final assessment results are composed of the scores and peacetime scores, and the proportion of the usual grades in the total scores is improved. The usual scores are composed of MOOC study level, MOOC discussion area participation, MOOC problem area scores and classroom performance, accounting for 50 of the final grades. \%. The overall design block diagram is shown in Figure 1.

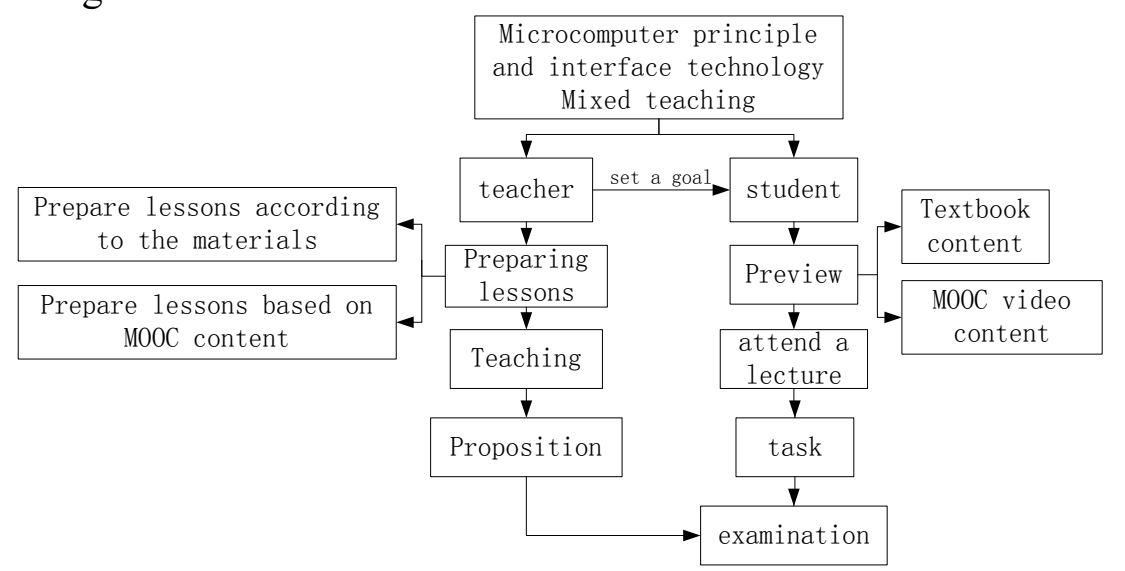

Figure 1. The overall design block diagram

MOOC teaching part design. The Microcomputer Principles and Interface Technology Course of the Chinese University MOOC Platform is organized by week for 12 weeks, covering 8 chapters, a total of 58 lectures, including overview of microcomputer system, microprocessor and bus, 80x86 basic instruction set, assembly language program. Involved, semiconductor memory, input and output and interrupt technology, programmable parallel digital interface, analog input and output. 
According to the syllabus of Xi'an FANYI University, the course includes a total of 64 hours, including 12 hours of experimental teaching and 52 hours of theoretical teaching. Therefore, the content of MOOC has been deleted, and 58 items have been reduced to 50 lectures. Arrange for 1-2 lectures on MOOC content. Students use the after-school time to learn MOOC videos, communicate in the problem discussion area after the video, and complete the corresponding chapter MOOC assignments. The block diagram of the MOOC teaching part is shown in Figure 2.

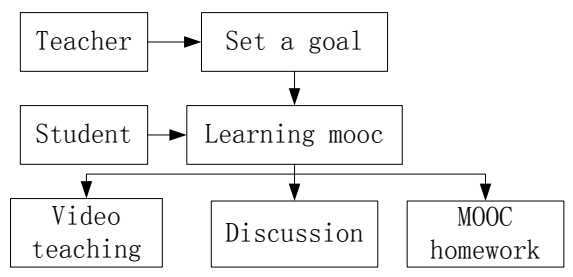

Figure 2. The MOOC teaching part design block diagram

Design of classroom teaching. The teacher first prepares lessons according to the outline and the content of the textbooks. Secondly, it monitors the students' learning situation, discussion situation and homework through the MOOC backstage, and sorts out the MOOC learning situation and problems of the students and focuses on the classroom learning. In the class, the teacher first explains the important knowledge points, and then exchanges the questions sorted in the preparation of the MOOC with the students, and finally arranges the corresponding exercises. The block diagram of the classroom teaching part is shown in Figure 3.

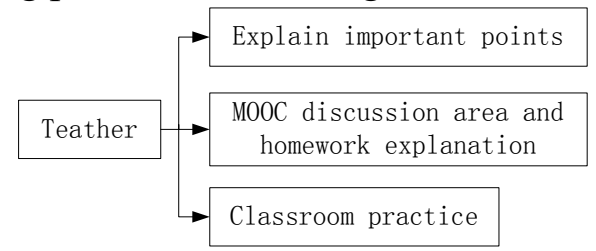

Figure 3. The part of the classroom teaching design block diagram

\section{Teaching effects}

The mixed teaching method of "Microcomputer Principles and Interface Technology" based on MOOC was tested in a small class of 36 people in the 2015 electronic information science and technology major of Xi'an FANYI University. Table 1 is the statistical table of the grades of the "computer principle and interface technology", which is the scores of the 2015 students and the 2014 and 2013 students of the same major.

Table 1 "Microcomputer principle and interface technology" grade statistics of each grade

\begin{tabular}{|c|c|c|c|c|c|c|}
\hline \multirow{2}{*}{$\begin{array}{c}\text { Fractional } \\
\text { segment }\end{array}$} & \multicolumn{2}{|c|}{2015 (36 people) } & \multicolumn{2}{c|}{2014 (36 people) } & \multicolumn{2}{c|}{2013 (36 people) } \\
\cline { 2 - 7 } & $\begin{array}{c}\text { Number } \\
\text { of people }\end{array}$ & Proportion & $\begin{array}{c}\text { Number } \\
\text { of people }\end{array}$ & Proportion & $\begin{array}{c}\text { Number } \\
\text { of people }\end{array}$ & Proportion \\
\hline $90-100$ & 10 & $27.80 \%$ & 7 & $19.40 \%$ & 6 & $16.70 \%$ \\
\hline $80-90$ & 9 & $25.00 \%$ & 8 & $22.20 \%$ & 6 & $16.70 \%$ \\
\hline $70-80$ & 8 & $22.20 \%$ & 11 & $30.60 \%$ & 13 & $36.10 \%$ \\
\hline $60-70$ & 8 & $22.20 \%$ & 5 & $13.90 \%$ & 7 & $19.40 \%$ \\
\hline $50-60$ & 1 & $2.80 \%$ & 3 & $8.30 \%$ & 3 & $8.30 \%$ \\
\hline Failed & 0 & $0.00 \%$ & 2 & $5.60 \%$ & 1 & $2.80 \%$ \\
\hline
\end{tabular}

The data in Table 1 shows that after one semester of study, after using MOOC mixed teaching, the scores of students are significantly higher than those of previous students, and the proportion of 
high scores is increasing[9]. Therefore, the MOOC-based "Microcomputer Principles and Interface Technology" course hybrid study The teaching method is appropriate, the students can master the basic knowledge of the course, the creativity is enhanced, and the overall teaching effect is good.

\section{Summary}

This paper analyzes the current situation and problems of the teaching of microcomputer principle and interface technology course, combined with the advantages of MOOC teaching, designed a hybrid teaching method based on MOOC "microcomputer principle and interface technology" course. This method requires students to work with teachers. Students need to do MOOC study before class, including watching video tutorials, discussing issues in the discussion area, and completing MOOC assignments. In addition to traditional preparation, teachers also need to prepare lessons for MOOC content, and collect MOOCs in advance[10]. The problem in learning is an important basis for classroom teaching. The practice shows that the hybrid teaching method based on MOOC "Microcomputer Principle and Interface Technology" can improve students' interest in learning, meet the diversified needs of students, and improve the overall teaching effect.

\section{Acknowledgements}

Fund Project: 2017 Shaanxi Higher Education MOOC Center Online Course Transformation Teaching Reform Research Project

Item Number: 17MZ59

\section{References}

[1] QinH, Cong L, Sun X. Accuracy improvement of GPS/MENS-INS integrated navigation system during GPS signal outage for land vehicle navigation[J]. Journal of Systems Engineering \& Electronics, 2014, 23(2): 256-264.

[2] Koyama Y, Tanaka T. The high-precision measuring method for motorcycle trajectory using GPS[J]. ICCAS-SICE, 2009: 3961-3965.

[3] Klaus Betre. Transmission Characteristics of Marine Differential GPS (DGPS) Stations [EB/OL].http://www.nensch.de/.

[4] Massimo Banzi. Getting Started with Arduino. Edition 2. O'REILLY, Beijing. 2013.

[5] Subhan F, Hasbullah H, Ashraf K. Kalman Filter-Based Hybrid Indoor Position Estimation Technique in Bluetooth Networks[J]. International Journal of Navigation \&Observation, 2013, 2013(1).

[6] Buck Rogers. AG-NAV 2 GPS/DGPS GUIDANCE SYSTEM. Ag Pilot International, 1997, 20(3).

[7] Congwei $\mathrm{Hu}, \mathrm{Wu}$ Chen, Shan Gao. Data Processing For GPS Precise Point Positioning. Transactions of Nanjing University of Aeronautics \& Astronautics, 2015, 22(2).

[8] Qadeer M A, Chandra A, Jain S. Design and implementation of location awareness and sharing system using GPS and 3G/GPRS[J]. International Journal of Multimedia and Ubiquitous Engineering, 2014,7 (4): 125-140.

[9] Dinkar A S, Shaikh S A. Design and Implementation of Vehicle Tracking System Using GPS[J]. Journal of Information Engineering and Applications, 2011,1(3):1-6.

[10] Leiek A. GPS satellite surveying[M]. John Wiley and sons, 2014:13-18. 